PLEASE NOTE! THIS IS SELF-ARCHIVED VERSION OF THE ORIGINAL ARTICLE

To cite this Article: Salin, O. \& Pesso, K. (2017) Open Minds, Open Spaces: Mindset Changes During Urban Walking. Space and Culture, 1-14. First Published June 21, 2017.

URL: http://journals.sagepub.com/doi/pdf/10.1177/1206331217705302

DOI: $10.1177 / 1206331217705302$ 


\title{
Open Minds, Open Spaces: Mind-Set Changes During Urban Walking
}

\author{
Ossi Salin and Kaija Pesso
}

\begin{abstract}
Our interest in this article is to explore how people reshape their mind-sets during walking in different urban places and spaces in the city. We argue that mind-set changes are socially mediated in relation to specific environments. Mentally closed environments can be opened through social interaction and social reflection of meanings of environments and spaces. This process presupposes personal experiences in environments and social closeness with others; it also presupposes familiarization with other people's social worlds and arenas. We present how people's interaction with environments, buildings, objects, and artifacts creates new meanings, affects people's social interaction and appreciations. Theoretical framework for understanding this process is constructed using social worlds/arenas theory based on symbolic interactionism and "embodied placemaking" assumptions. Our methodology of is called video-recorded walking combines principles of walking ethnography and video ethnography. In the analysis, we pay attention to key situations and moments which transform people's mind-sets.
\end{abstract}

\section{Keywords}

urban walking, mind-set, ethnography, embodied placemaking, social worlds/arenas

\section{Introduction}

Different kinds of participatory approaches have been applied in urban development from the late 1970s. Participatory methods have developed from accurate and detailed information gathering, especially in the late 1980s through interactive models in which information and knowledge is produced in social exchange among various actors (MacCallum, 2009; Mitlin \& Thompson, 1995). Since the early 1980s, aspects of sociomateriality came to use in a range of disciplines such as sociology and human geography (Jones, 2013), the latter of which contributed to understandings of the centrality of the human body in placemaking. Bodily movement in this sense is seen to produce different kinds of places (Sen \& Silverman, 2014). MacCallum (2009) who has applied critical discourse analysis at governance practices and community development research highlights the role of discursive practices and knowledge construction in space/place production. In her model, communication builds and maintains social and personal relationships, reproduces epistemologies, organizes and stores information, and pursues strategic goals (MacCallum, 2009). Relevant to our research perspective is her argument that it is important to pay attention not only to spaces and participants (people) but also how languageincluding gestures, graphics, layouts, built structures—is used. Language may be more or less open, accessible, inclusive, inspiring, responsive, and creative (MacCallum, 2009).

Urban walking - in various forms-may produce interesting experiential knowledge for community development. Walking is essentially a social event and during a walk something happens in people's thinking, imagination, and emotions. Our walking was carried out in a research project called "Caring, Sharing Networks in Southern Finland at Espoo City.” The project's goals were to enhance residents' participation and develop efficient means for stakeholders and residents' collaboration in urban development. Our aim was to explore how people reshape their mind-sets during walks in different places and spaces. What happens in moments and situations and what kinds of elements make mindset changes possible?

\section{Concepts and Theoretical Approach}

In our understanding, the concepts of place and space also have a close relation to the concept of situation. Situation combines contexts, including places, of action and agency, so it opens a broader perspective for consideration. According to Clarke (2005), a situation is always greater than the sum of its parts because it includes their relationality in a particular temporal and spatial moment. Clarke (2005, p. 35) says that the term "situation" is broader than "situated face-to-face interaction" or "sites of interpretive practice"; it includes pertinent institutional and other mesosocial/macrosocial formations. According to Clarke (2005), situations are relational and ecological and they are defined in their consequences. She continues by saying that people and things, humans and nonhumans, fields of practice, discourses, disciplinary and other regimes/formations, symbols, controversies, organizations, and institutions, each and all can be present and mutually consequential. Clarke does not actually develop a theory of situations, it is more like a theory or 
framework of how to analyze situations. It is an ambitious approach to understand a big picture of social reality under investigation.

It is critical what kind of epistemological approach we assume in research of situations or in spatial analyses of many kinds. Sen and Silverman (2014) place human experience and human body at the center. According to them, a physical environment cannot exist without the human inhabitants who experience it in their everyday lives, and its meaning is dependent on the larger political and economic contexts within which these individuals operate. They argue that spatial analyses in fields that deal with built environment often neglect the body because of difficulties in resolving the dualism of the subjective and objective body and distinctions between the material and representational aspects of body space. There is a need for theoretical concepts to interweave experiential, cognitive, and/or emotional understanding of the intersection and interpenetration of body, space, culture, and material and experiential intersection (Low, 2014). Sen and Silverman (2014, p. 2) suggest a concept called "embodied space.” They go still further by arguing that "embodied placemaking” as a category of analysis is foregrounding not only place but also the body's role within it as mutually constituent elements of the built environment. Low (2014, p. 41) says "that embodied space and bodily movement produces different kinds of places.” According to her, it locates the body in the center of all placemaking activity, and it makes the body an important component of the social production of space. In addition, Low (2014) synthesizes material and nonmaterial into one by defining that embodied space is the location where human experience and consciousness take on material and spatial form (Heylighen \& Strickfaden, 2012).

We think that "embodied space" and "embodied placemaking” are relevant concepts for understanding a dynamic relation of human agency and environment. Low (2014, p. 20) associates spatial orientation and mobility and movementparticularly walking - in a "placemaking” process. We would like to bring alongside movement or walking another dimension of human existence in a space, the presence and social interaction. This does not mean just passive stability in a place, it is rather a reflection and social reframing of and in situations. So from experiential viewpoint, we suggest that Clarke's situational analysis could accordingly be interpreted as “embodied situational analysis.” This would emphasize experiences as an analysis perspective. Situational analysis is grounded on social worlds/arenas/discourses theory, which originates from the Chicago School symbolic interactionism and early social ecology. The recent development of situational analysis concerns taking the nonhuman explicitly into account including material "things" and discourses (Clarke, 2005).

There are different definitions of social worlds. According to Clarke (2005), Mead (1972) described social worlds as universes of discourse, Shibutani (1986) viewed social worlds as identity- and meaning-making segments in mass society, Strauss (1978) and Becker $(1974,1982)$ defined social worlds as groups with shared commitments to certain activities sharing resources of many kinds to achieve their goals and building shared ideologies. We can say that social worlds as a concept has multiple dimensions like shared commitments, discourses, actions, identities, and meaning-making segments. In addition to these, we think that actors do not represent social worlds that are just their own. They may represent other people's social worlds as well like their clients and stakeholders. Lindell (2016) highlights interestingly how spaces and places are created in the media in various ways. This viewpoint may for one's part explain why certain kind places seem to more open to people than others according to nature of messages assumed from media. From the social worlds/arenas perspective people participate in a number of social worlds/arenas simultaneously and they are sites for meaning making and identity construction. Arenas are discursive sites in often complicated ways and arenas are not just sites or places for harmonious collaboration but they are sites of competition and arenas of exercising power as well (Clarke, 2005).

Earlier in this article, we highlighted a fundamentality of the body and consciousness at all placemaking activity. Consciousness refers to the wholeness of perceptions, experiences, emotions, remembrances, and thoughts, which an individual has at a moment. Consciousness may still remain to some extent as a little general level compared with a concept called mind-set. There are obvious similarities, but mind-set as a concept includes valuations, interpretations, and goal setting; it refers more to an individual as an actor and it links environments and individuals together on mental level. Mind-set is defined in a dictionary as "a habitual or characteristic mental attitude that determines how people will interpret and respond to situations” (HyperDictionary, 2013). Fang, Kang, and Liu (2004) define mind-set as the basic assumption, beliefs, core values, goals and expectations shared by a group of people who are committed to a specific field, and what they will use as rules to guide their attitudes and practice in the field. In a way, this definition of mind-set resembles quite a lot what Clarke has presented about people's social worlds. Even if they seem to look quite similar, we think that they emphasize social and psychological aspects in a different way. Social worlds refer more to social processes and social groups and mind-set as a concept refers to processes which are happening in people's minds. Social worlds/arenas theory does not specify how social worlds are changing — especially on individual level-but some of the theorists concerning the mind-set approach think that mind-set changes are necessary to happen on three domains: cognitive, behavioral, and affective (Fang et al., 2004).

Doorewaard and Benschop (2003) highlight the meaning of positive emotional experiences at these changes, particularly in case we would like to promote changes into certain kind of direction; for instance, if we would like to help people feel places more comfortable and inviting. 


\section{Methodology}

\section{Data Gathering}

Ingold and Vergunst (2008) say that walking is profoundly social activity and the feet respond as much as the voice to the presence and activity of others. The social nature of walking is grounded on a movement that is both rhythmically resonant with the movements of others around us and whose journeys we share or whose paths we cross. They claim that social life is in essence "walked" and we need careful, ethnographic analysis of walking which actually helps us rethink what being social actually means. Body itself is grounded in movement and "walking is not just what a body does; it is what a body is" (Ingold \& Vergunst, 2008, p. 1). We understand these arguments as an attempt to relocate "social” from a discursive domain into a more material realm. This ontological position leads us accordingly to ask epistemological questions like how to get knowledge from a social life and, especially, how to communicate about this.

Walking can be understood as a way of thinking and feeling (Bourdieu, 1977; Ingold \& Vergunst, 2008) or thinking in a movement (Sheets-Johnstone, 1999). We think that besides walking, we need moments of immobility or at least slower mobility, feeling of presence with others (Legat, 2012). We may say "thinking and sharing with others close to you” or "just being present with your inner thoughts and emotions in a situation" (Bourdieu, 1977, pp. 93-94; Ingold \& Vergunst, 2008). It is challenging to conceptualize these kinds of situations from outside. Lived experiences are changing and constructing and reconstructing all the time. Information exchange and construction are just partly in spoken words, communication is "embodied" and this means that our observations and narratives of situations remain somewhat incomplete. Despite this incompleteness, we try to observe walking and situations through those elements recommended in situational analysis and pay attention to critical moments where possible mind-set changes_-on cognitive, behavioral, and affective levels - may happen. Here, we have to listen to people's spoken words, observe their movements, and reflect impressions in situations.

We recorded this walk under investigation with one iPad. It was carried inconspicuously against the researcher's own body and that is why it is swaying in the rhythm of walking and follows body movements. Even though participants were informed about the recording, we did not record people visually very much. This was done for privacy reasons (Capstick, 2012) and because we wanted to keep situations and discussions as natural as possible. We took photographs, too, to enrich data gathering. We define our data gathering simply as a video-recorded walking, which has adopted features from walking ethnography and video ethnography. Ethnography itself has various definitions. According to Ivarra and Aguero (2009), ethnography is a research-based method on observing people in their natural environment. Falzon (2009) defines ethnography as a methodology which entails the situational combination of field techniques like note taking, audio/visual recording, interviews, and participatory observation. It is based on trust and interaction between researcher and researched and data are produced in this interaction.

According to Yi'En (2013), walking ethnography focuses on the act of walking as a mobile and embodied practice and it comprehends the sensorial aspects of bodies such as seeing, hearing, and feeling. He refers to Wunderlich's (2008, p. 132) notion of "discursive walking" as a participatory mode of walking, during which we half consciously explore the landscape, while sensorially experiencing it passing by. He continues by saying that walking and photographing-he suggests video-recording technics, too-is rhythmical and brings our bodies into "conversation" with the environments we move through. In this sense, this kind of video documenting could be called "participatory video methodology," because it can be used as a tool for community and urban development (Corneil, 2012, p. 19). Video ethnography may be accordingly defined as one application of visual ethnography and as a methodology which observes and records visually the embodied, social and material practices, technologies, and performances (Pink, 2012).

\section{Applied Situational Analysis}

We recorded about 3 hours audiovisual material without pauses-except one accidental short pause during the walk. After this, we have watched the material several times and made notes and transcriptions using "free flowing word technique."

Transcription examples:

When walking begins, people started to speak about their personal memories. Mild walking but windy weather. What made you participate in this walk? My boss ordered me!

Atmosphere is a core which created in interaction. Presence-two kinds of ways to communicate, an objective way or a subjective way to communicate. Subjective way to communicate is a language of presence. Objective way to communicate is a language of professional treatment. We are sitting, interaction, feeling of presence, homelike warm.

Here are seen a Hindu tapestry, orthodoxies religious icons, written greeting of Muslims. Orthodox artefacts haven’t make any harm. 
We applied Clarke's situational analysis technique-an abstract situational map (Table 1) she suggests as basis for more detailed analysis process. Clarke has developed the situational analysis within grounded theory framework and suggests that it allows researchers to draw together studies of discourse and agency, action and structure, image, text and context, and history and the present moment— to analyze complex situations of inquiry broadly conceived. Clarke (2005) presents three different kinds of cartographic approaches or "analytic exercises" which are intended to provoke the researcher to analyze (situations) more deeply. These approaches can be used with coded data or with uncoded but carefully read and somewhat "digested" data.

A situational map should include all analytically relevant human and nonhuman material and symbolic elements of a particular situation as framed by those in it and by the analyst. Clarke (2005) suggests here abstract situational maps (messy/working version and ordered/working version) to identify essential and relevant elements related to the situation under investigation. Unlike Clarke, we did not apply cartographic mapping or drawings in our analysis. But, we observed during the walking and at data processing those elements—human and nonhuman material—she presents for analysis framework. We made notes and descriptions of environments, places, people, ways of communication, issues of communication, nature of interaction, atmosphere, artefacts, and experiences lived and expressed. Some of the elements were found in people's discourses, others were visually observed.

Even though Clarke (2005) favors categorizations which can be conducted informally in analysis (even in a "quick and dirty" way), we did not want to make strict categories, because we preferred to keep analysis flowing and moving, as a reflection of reality itself. In addition, we thought that categorization may easily lead to different kinds of dichotomies, which would not actually follow our theoretical positions of "embodied spaces" or ethnographic approach either.

We tried to pay special attention to elements related to mind-sets—cognitive, behavioral, and affective domains — and its possible and perhaps observable changes. Construction of a general view of this is based on details, sometimes on bypassing and fragile moments in situations where people were talking and using a special tone in their voice, moving in a space in a special way. We listened to their questions, comments, and what they said afterward of situations: What they have learned and what they have felt. Sometimes we trusted impressions. After all, our solution in analysis is thus one kind of narrative constructed through situational analysis elements enriched with mind-set aspects.

\section{Findings}

In this research, we conducted three walks in different environments. In this article, we discuss the first of them. The walk consisted of six visit places in the center area of the city of Espoo and the aim of these organized walks was to get familiar with a few locations and activities happening there. These visits were part of the development of a local community center and the key issue was, that is, a real need for new places for residents. Another question was related to the nature of planned activities there. People were invited to walks through different channels, but finally just six participantsincluding the researcher - came along. The walk was organized and guided by an architect who was going to gather data from participants' assessments of suitability of places for residents' activities.

Table 1. Abstract Situational Map, Ordered Working Version (Clarke, 2005, p. 90). 


\section{INDIVIDUAL HUMAN \\ ELEMENTS/ACTORS}

e.g., key individuals and significant (unorganized) people in the situation

COLLECTIVE HUMAN ELEMENTS/ACTORS

e.g., particular groups; specific organizations

\section{DISCURSIVE CONSTRUCTIONS OF INDIVIDUAL AND/OR COLLECTIVE HUMAN ACTORS}

As found in the situation

\section{POLITICAL/ECONOMIC ELEMENTS}

e.g., the state; particular industry/ies; local/regional/global orders; political parties; NGOs; politicized issues

\section{TEMPORAL ELEMENTS}

e.g., historical, seasonal, crisis, and/or trajectory aspects
NONHUMAN ELEMENTS/ACTANTS

e.g., technologies; material infrastructures; specialized

information and/or knowledges; material "things"

IMPILICATED/SILENT ACTORS/ACTANTS

As found in the situation

\section{DISCURSIVE CONSTRUCTION OF NONHUMAN ACTANTS}

As found in the situation

\section{SOCIOCULTURAL/SYMBOLIC ELEMENTS}

e.g., religion; race; sexuality; gender; ethnicity; nationality; logos; icons; other visual and/or aural symbols

\section{SPATIAL ELEMENTS}

e.g., spaces in the situation, geographical aspects, local, regional, national, global spatial issues

\section{MAJOR ISSUES/DEBATES (USUALLY CONTESTED)}

As found in the situation; and see positional map OTHER KINDS OF ELEMENTS

As found in the situation

The walk started at a location situated in a new shopping center. This location served as an event and encounter place for residents planning a forthcoming community center. The starting point was basically just an empty hall, which was partly decorated with chairs and tables. The walls of the place were here and there covered by posters, pictures, maps, and paper sheets where people were able to write their proposals and opinions of the planned community center. Information sheets concerning ongoing community center development were scattered on tables. The shopping center itself represented a modern high-tech environment and restless consumerism.

It was a rather short walk from the shopping center to the first visit place. The weather outside was sunny but a little bit cold and windy. Some of the participants already knew each other from other contexts but others were unknown. I was curious to know what actually motivated one of the ladies to join the walk and she replied that her superior in a library asked her to do that. Another lady said that she was especially interested in one building on the route. The route took us through a railway station which splits the city center in two. Simply saying the city half with the big shopping center represented modern rapidly changing urban environment and the other half, we were going to, represented history and tradition. We were approaching the first visit place and people were fascinated by early spring flowers growing along the sidewalk.

The first visit place (Figure 1) was over 100 years old Villa, which was originally built as a private residence on the countryside, but in the course of time, the city development shrank the country-style environment around the Villa. Despite surrounding urbanization, the location of

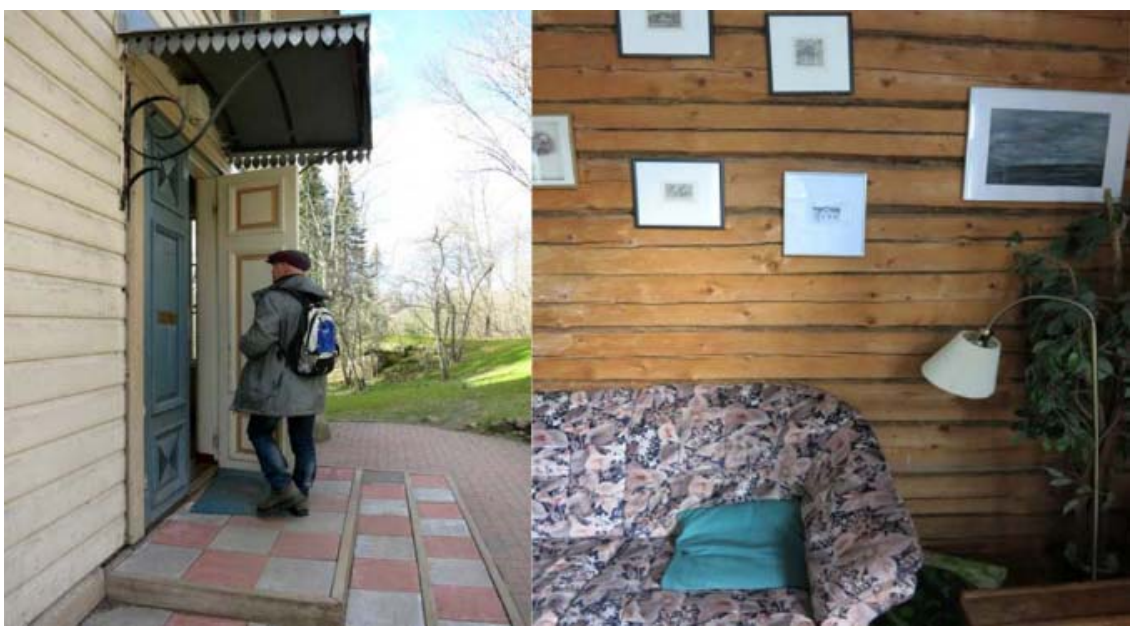


Figure 1. Situational analysis elements: History, landscape, atmosphere (2015). Source. Image courtesy of Anna-Leena Mutanen.

the Villa is harmoniously engaged to the traditional environment — even though rather small one — with a medieval church and a few traditional buildings. The Villa ended up in the possession of the city and in the beginning of 1990, the mental health association renovated the building for activities of the association. The walkers were warmly welcomed inside and to meet people there. First impressions were human warmth, timber walls, history, and joy. Our guide explained the purpose of the walk to the people present there and asked them to tell about the activities going on there. The association's staff explained their mission as a low threshold encounter place for people. Even if the association's name refers to mental health, they consider themselves more as an association of culture and sport or exercise. The policy is that no one's diagnostics is asked. It does not matter very much, everyone is welcomed as they are. Activities in the place were various like different kinds of parties, communal work including cooking, eating meals together, cleaning, mailing, and so on, having tea and coffee together or just hanging around, it was possible to meet other people or surf on the Internet, play with different instruments.

The visitors were told about the history of place and its environment. History was very clearly seen on the walls, windows, pictures, and furniture. The wooden white Villa was built in 1904 and it is nowadays protected by the Finnish National Board of Antiquities. People of the association emphasized the history of the building and they explained details with the help of old pictures on the walls. We heard descriptions of former inhabitants like mothers with illegitimate children, who lived in tiny cottages on a hillside close to Villa. Many old buildings, like the cottages and a cow house, have over the years been pulled down and fields have disappeared. People became aware of the changes in the nearby environment, but understood that something has still been sustained in this building, on the wooden walls, windows, and people's stories and recalling. The visitors were fascinated because of all this and someone expressed her gratitude for hearing about the history of the place. The visitors were free to look around in the place and on the upper floor they saw and heard associate members training Eric Clapton's song “Cocaine.” There were a couple of smaller rooms, one of them served as an office and another was reserved for discussions. Prominent timber walls in the office impressed the visitors again. They paid quite a lot of attention on a window at the top of the stairs. It rose up right from the floor, which they saw as a modern solution in this old building. Altogether, the atmosphere in the place was warm, cozy, and contained with acceptance. Time started slightly to slow. We thought that the mind-set of the people of the association-which has developed over the years in this environment-was embodied in their attitudes, valuations, discourse, and actions. Their way of being present with their clients was similar to the way of being with us. Through discussions, experiencing, and sharing, the space and possibilities opened to us in a different way.

After this, we moved to the second place (Figure 2) next to the previous one. It was a 94-year-old pharmacy building "Villa pharmacy," which served now as another low threshold encounter place for people of many kinds. Two staff members of the place warmly welcomed us and we were invited to a smaller meeting room than the one in our first visit place. We were told about the nature of activities there and the most remarkable client group was rehabbers of substance abusers. But other groups gathered there as well, such as the Finnish Red Cross, Yoga hobbyists, immigrants, and mental health rehabbers. Basically, anyone was allowed to come and start running a new group or other activities there. They told us that the Villa was actually the first pharmacy in this part of the town. In those days, the apothecary on duty has brought different kinds of herbs from abroad and planted them in the garden. This diversity of plants may still explain why the university counted over 600 species of butterflies in the neighborhood. The staff of the place called this area "pocket of the nature."

One of the workers emphasized the significance of the atmosphere, which is created there through social interaction. If this were missing, everything would remain shallow and empty. Presence with others is the most important thing. He explained that there are two kinds of discourse: a discourse making people objects and a discourse making people subjects. According to him, a professional way to communicate alienates people from each other and destroys presence or closeness among people. This is the reason why they have given up professional roles and ways to speak.

The visitors admired the coziness of the space and felt very comfortable. They paid attention to the windows and the warm light streaming in. One of the visitors described the space as homelike and said that she could stay and live there. The room we gathered in appeared as a calming, easy opening, and easygoing space which supported mental concentration. It seemed that the visitors would have liked to stay there for a longer time, but paradoxically we had to follow the schedule and leave. They said farewell to us and we felt relaxed, and we were encountered and our inner rhythm was obviously slower. One of the walkers commented to us outside that it would be great if you could just go there and relax for 15 minutes in the middle of the workday. That would improve personal well-being. After these two visits, in these very similar kinds of places, which were breathing the same kind of atmosphere, we noticed that we had somehow been touched. The walkers had heard something about social worlds they were not that familiar with before. They also got information about places, people, activities, and history, which means processing things on a cognitive level in the mind. In addition, the walkers were affected on an emotional level because of the qualities of the places and the nature of discourse and interaction. The social and ethical principles which were embodied in these places and the people, were embodied in us too, to some extent. One of the walkers said that she did not realize that these places would be open to her too. She said that she has just passed by these places for years. Now, they were open in her mind. 
The third place (Figure 3) was an old school building which was taken care of by the local Finnish Swedish culture association. The route there went through an old cultural landscape by a narrow river. The walkers discussed the impressions they got from the previous visit places and butterflies in the beautiful spring weather. Approaching the visit place, there was a red wooden building constructed in the year 1873. One of the visitors remembered that Lev Tolstoy published his famous novel Anna Karenina in the same year. The door was invitingly open and we were welcomed by an old lady who spoke in a rather silent way. The visitors noticed pictures of all the Finnish presidents on the wooden walls. The lady told us about the history of the house. Originally the house served as a school, later as an office of the City, and now after renovation it was a place for hire for different purposes. There was a school museum on the second floor. The place was not open and free but it could be hired for meetings, family parties, education, and concerts. The visitors walked around in the rooms, and admired politely

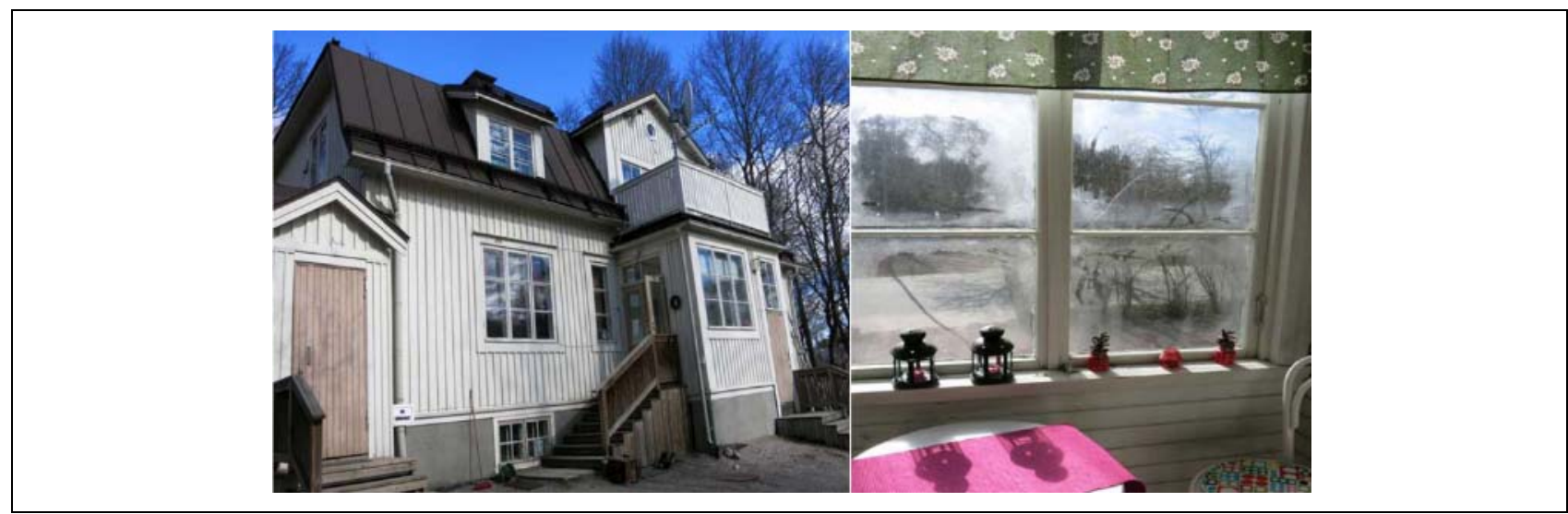

Figure 2. Situational analysis elements: Building, environment, presence, atmosphere (2015). Source. Image courtesy of Anna-Leena Mutanen.

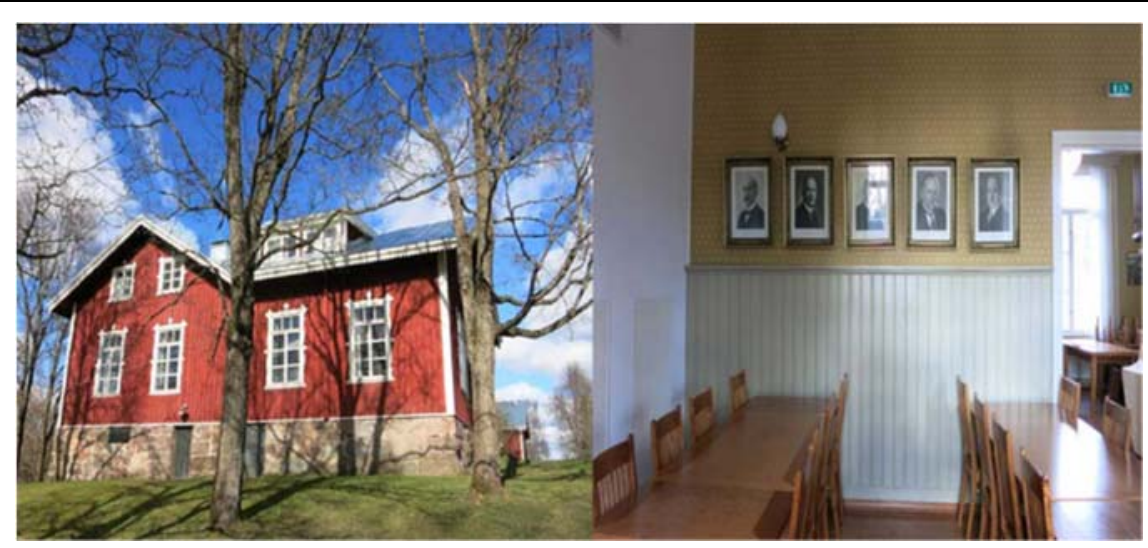

Figure 3. Situational analysis elements: History, landscape, strict order (2015). Source. Image courtesy of Anna-Leena Mutanen.

the beautiful space and environment. Compared with the previous places, the visitors were standing and moving around, for some reason the visitors did not seat themselves. The atmosphere in the place was a little bit mild and silent. It was not such a social encountering place like the two others. It was not a low threshold social space which might explain the atmosphere. In addition, there was just one person who was discussing with us. When we started our walking to the next place, we did not actually reflect the nature of the place we just visited.

The walk to the fourth place (Figure 4) was remarkably longer than before and the landscape changed. We left the old culture environment behind and moved to an area with apartment buildings and cement. We became aware of noise of traffic, gravel rustled under our feet. It was still sunny and windy. The place was situated on the first floor in an apartment building. We were welcomed inside in a friendly manner and we gathered in a pleasant living room which served as a meeting room, as well. Our host was busy for a few minutes in the beginning and the visitors were allowed to discuss among themselves about the space they were in and other things. The visitors discussed the meanings of places and spaces for instance, who are allowed to use these places. They wondered if places were open to everyone or are they labelled for certain kinds of people or groups. Our host apologized for her delay and she welcomed us again and asked us to have a coffee. There were orthodox icons on the walls and other artefacts like paintings and colorful wall carpet which aroused debate. 


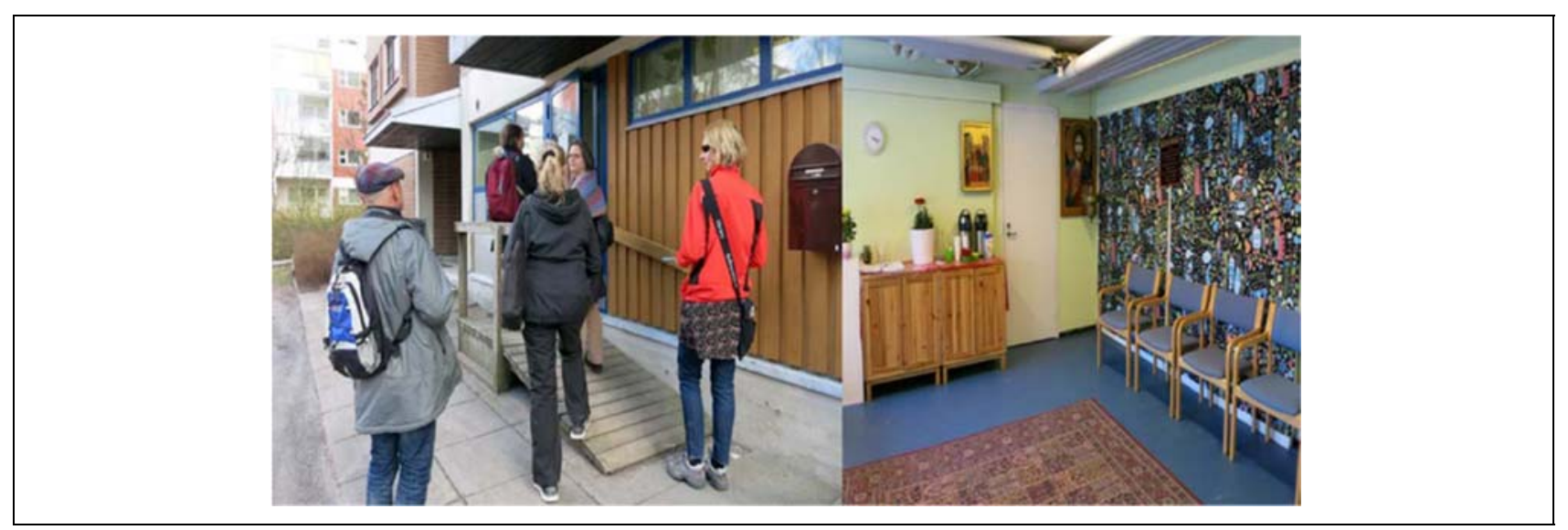

Figure 4. Situational analysis elements: Environment, icons, artefacts, esthetics (2015).

Source. Image courtesy of Anna-Leena Mutanen.

The place was an international meeting place maintained by an association. It was a common living room gathering people from different cultures. There were many kinds of activities offered like Finnish language courses, groups for handicrafts, religious groups, and other kinds of meetings and gatherings. The staff were able to offer counselling services for immigrants, for instance, in a case of language difficulties. They arranged multicultural food parties and the aim of the association was to promote dialogue among different cultures and religions. Hospitality and respect were important principles of the association and action. They saw the possibility to maintain one's own cultural identity as very important. Despite this, one member of the association emphasized the importance of Finnish language skills, because it would help people integrate to and cope in Finnish society. Our host stated that their place was not fully open to everyone because activities have to be related to multiculturalism and religion. She referred repeatedly to trust if someone would like to arrange some kind of activity there. She said that somehow it must be assured that the activity would follow their principles and policy.

The visitors seemed to have great feelings after this place. We wondered why there is suspicion among immigrants toward protestant church and spaces and why orthodox culture is easier to approach. We wondered if this were because of the suitability of spaces for activities or is it more a question of mental suitability. We started to walk to the last visit place. Our route passed by an area under construction. During the walk, walkers discussed city development, construction, and environment. Discussion was lively and focused on actual issues in city development.

The last visit place (Figure 5) was in a suburb situated on a hill covered by several apartment buildings. The visit place was on the first floor of one rather high building. A playground for children was in front of the place. We heard that there are many people on the playground in the summertime. We entered into a cozy living room with paintings and other artefacts on the walls. The chairs were colorful, soft and comfortable, and a white piano was in a corner. We were hosted by a project worker. We felt welcomed and the atmosphere was calm and easy. The place was run by a project that helped people with housing problems. The clients consisted mainly of multicultural and homeless families. According to a staff member, housing problems are often connected to other problems in people's lives. Their clients come to them from different social services and the project tries to build bridges between the city and the inhabitants. The project defines itself as the "eyes and ears" of the area. This place was not open to everyone because they are doing intensive family work.

At the end of this last visit, we discussed and reflected experiences and thoughts concerning the walk and visits. The participants expressed that the walk was rather long and took

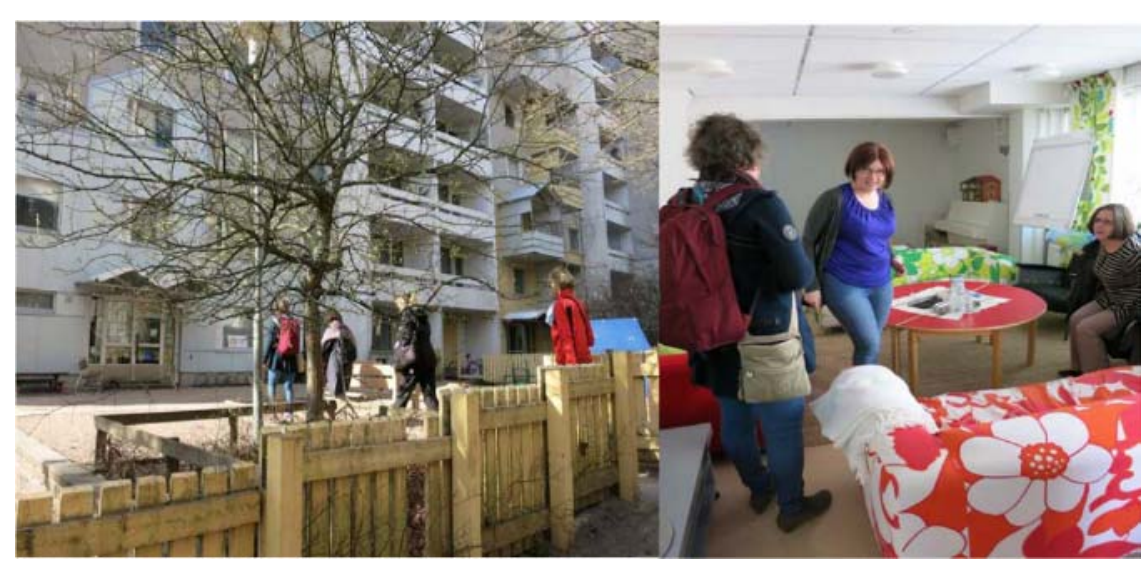


Figure 5. Situational analysis elements: Building, cement, artefacts (2015). Source. Image courtesy of Anna-Leena Mutanen.

over 3 hours. After all they said it was good because of positive and nice places. Two of the participants were already familiar with these places, some of walkers did not even know these places existed before this. The discussion developed slightly into personal experiences. Our guide asked us what kind of impression we got of the places. The walkers' opinions were that some of the places and spaces were more closed than others, in principal they were open but mentally closed. One of the visitors said that she knows right away, when she opens a door, whether this is her place. There was the opinion that the first two places were possible and open to them. Overall, the places were good by atmosphere and there were various activities. After this discussion and reflection, our walk was completed.

\section{Discussion}

Our intention in this article was to highlight the significance of mind-set changes of residents as a key to open spaces and places for people and in this way to advance regeneration of cities. Our theoretical approach was essentially underpinned by assumptions where experiences in and of "embodied space” and bodily movements would produce different kinds of places. Even though feasible mind-set changes would not be radical and directly observable, we were able to make observations of how people expressed themselves, what and how they talked, how they moved, and how they were present in places and with other people; for instance, the walkers' expressed evaluations and emotions during the walk and visits were observable. It may be too early, anyway, to say that feasible mind-set changes really happened and they would remain, but despite this uncertainty, we can say what kinds of things most likely would promote this. What kinds of things most likely would “open minds” for impressive experiences in places and produce a new kind of "embodied” understanding of accessibility of different places.

First, we have to take into account all three domains of mind-set: cognitive, affective, and behavioral domains. The walk we researched seemed to work on all of these dimensions. The participants got information of the visit places, they got positive experiences on an emotional level, and they were involved in discussions with other people. We noticed that there are several things which matter and which are merged. There must be the opportunity to encounter other people, have an easygoing and peaceful dialogue with them. People are usually representing different kinds of social worlds and they are acting on arenas of their own. Therefore, it is important that people were able to share their experiences, knowledge, impressions, and feelings in relation to the place they are present. This dialogue presupposes time, presence, and mutual trust. Our experiences of urban walking as a social and discursive event resemble quite much Aoki and Yoshimizu's (2015) reflections on their fieldwork. The meaning of talking, sharing stories, and presence were important in our research as well.

Time played different roles in our walk and visits. Especially in the first visit places, the history of the places and environment was prominently present: It was told, it was seen in materials and artefacts. Growing awareness of the history seemed to deepen experiences and the valuation of places. The way in which the visitors were encountered created a feeling of presence. This rather strong experience of presence affected the visitors in a way which they described as a slowing time. This "lingering time" may originate somewhat from ideologies and discourse which were represented by the actors of the visit places. They have given away the "traditional” professional way to be with their clients and way to discuss with them. They emphasized the principle according to which to be a human to a human was the most important thing. Nevertheless, we think that time would — in one way or another-be one of the most important elements in a mental regeneration of cities.

Doorewaard and Benschop (2003) highlighted earlier a meaning of positive emotional experiences for mind-set changes. It is certainly a very personal thing because of personal history, valuations, environment, and so forth. Despite this variety of personal backgrounds and objectives of people, there is still something common among people. Certain kinds of places are experienced as more comfortable and inviting compared with others. Old wooden buildings and spaces seem to be more pleasant than modern concrete constructions. But at least as important are other people and the nature of their social interaction. We paid attention to an atmosphere prevailing in places which was a combination of different human and nonhuman elements. It was very interesting to perceive how history, environment, artefacts, materials, and discourses were embodied in those places and people and how something from all of this was embodied in ourselves; sometimes, even in a therapeutic way.

Our methodological combination of principals of walking and video ethnography was a flexible and suitable approach to understand the social nature of urban walking. Situational analysis elements helped us observe and understand what happened during our walk and situations. Through situational analysis elements, it was possible to pay attention to those details which might promote mind-set changes. "The silence of the 'users"” could be heard and abstract spaces would be changed to concrete places with possibilities (Lefebvre, 1991; Shields, 2013).

\section{Authors' Note}

This article was presented at the Workshop on Revealing Hidden City, First International City Regeneration Congress 2015 in University of Tampere, September 3 and 4, 2015. 


\section{Declaration of Conflicting Interests}

The author(s) declared no potential conflicts of interest with respect to the research, authorship, and/or publication of this article.

\section{Funding}

The author(s) disclosed receipt of the following financial support for the research, authorship, and/or publication of this article: The authors received financial support for the research, authorship, and/or publication of this article from Development Program for Residential Areas 2013-2015, ARA: the Housing Finance and Development Centre of Finland, the Ministry of the Environment.

\section{References}

Aoki, J., \& Yoshimizu, A. (2015). Walking histories, un/making places: Walking tours as ethnography of place. Space and Culture, 18, 273-284.

Becker, H. S. (1974). Photography and sociology. Studies in the Anthropology of Visual Communication, 1, 3-26.

Becker, H. S. (1982). Art worlds. Berkeley: University of California Press.

Bourdieu, P. (1977). Outline of a theory of practice (R. Nice, Trans.). Cambridge, England: Cambridge University Press.

Capstick, A. (2012). Participatory video and situated ethics: Avoiding disablism. In E.-J. Milne, C. Mitchell, \& N. de Lange (Eds.), Handbook of participatory video (pp. 269-282). Lanham, MD: AltaMira Press.

Clarke, A. E. (2005). Situational analysis: Grounded theory after postmodern turn. London, England: Sage.

Corneil, M. K. (2012). Citizenship and participatory video. In E.-J. Milne, C. Mitchell, \& N. de Lange (Eds.), Handbook of participatory video (pp. 19-34). Lanham, MD: AltaMira Press.

Denzin, N. K. (2004). Symbolic interactionism. In U. Flick (Ed.), A companion to qualitative research (pp. 81-87). London, England: Sage.

Doorewaard, H., \& Benschop, Y. (2003). HRM and organizational change: An emotional endeavor. Journal of Organizational Change Management, 16, 272-286.

Falzon, M.-A. (2009). Introduction. In M.-A. Falzon (Ed.), Multi-sited ethnography: Theory, praxis and locality in contemporary research (pp. 1-23). Abingdon, Oxon, England: Ashgate.

Fang, F., Kang, S., \& Liu, S. (2004). Measuring mindset change in the systematic transformation of education. Retrieved from http://files.eric.ed.gov/fulltext/ED484992.pdfFlick, U. (2004). Constructivism. In U. Flick (Ed.), A companion to qualitative research (pp. 88-94). London, England: Sage.

Flick, U., von Kardorff, E., \& Steinke, I. (2004). What is qualitative research? An introduction to the field. In U. Flick (Ed.), A companion to qualitative research (pp. 3-11). London, England: Sage.

Heylighen, A., \& Strickfaden, M. (2012). \{lm \}materiality: Designing for more sense/s. Space and Culture, 15,180-185.

HyperDictionary. (2013). Meaning of mindset. Retrieved from http://www.hyperdictionary.com/ search.aspx?define=Mindset

Ingold. T., \& Vergunst, J. L. (2008). Introduction. In T. Ingold \& J. L. Vergunst (Eds.), Ways of walking: Ethnography and practice on foot (pp. 1-20). Hampshire, England: Ashgate.

Ivarra, A., \& Aguero, P. (2009). Contemporary studies in ethnography. Hauppauge, NY: Nova Science.

Jones, M. (2013). Untangling sociomateriality. In R. Carlile, R. Nicolini, A. Langley, \& H. Tsoukas (Eds.), How matter matters: Objects, artifacts, and materiality in organization studies (pp. 197-226). Oxford, England: Oxford University Press.

Lefebvre, H. (1991). The production of space (N. Donaldson-Smith, Trans.). Oxford, England: Basil Blackwell. (Original work published 1974)Legat, A. (2012). Walking stories: Leaving footprints. In T. Ingold \& J. L. Vergunst (Eds.), Ways of walking: Ethnography and practice on foot (pp. 35-49). Hampshire, England: Ashgate.

Lindell, J. (2016). Communication as spatial production: Expanding the research agenda of communication geography. Space and Culture, 19, 56-66.

Low, S. (2014). Placemaking and embodied space. In A. Sen \& L. Silverman (Eds.), Making place: Space and embodiment in the city (pp. 19-43). Bloomington: Indiana University Press.

MacCallum, D. (2009). Discourse dynamics in participatory planning. Farnham, Surrey, England: Ashgate.

Mead, G. H. (1972). The philosophy of the act. Chicago, IL: University of Chicago Press. (Original work published 1938)

Mitlin, D., \& Thompson, J. (1995). Participatory approaches in urban areas: Strengthening civil society or reinforcing the status quo? Environment and Urbanization, 7, 231-250. Retrieved from http://eau.sagepub.com/content/7/1/231.full.pdf+html

Pink, S. (2012). Advances in visual methodology. London, England: Sage.

Sen, A., \& Silverman, L. (2014). Embodied placemaking: An important category of critical analysis. In A. Sen \& L. Silverman (Eds.), Making place: Space and embodiment in the city (pp. 1-18). Bloomington: Indiana University Press.

Sheets-Johnstone, M. (1999). The primacy of movement. Amsterdam, Netherlands: John Benjamins University Press.

Shibutani, T. (1986). Social processes: An introduction to sociology. Berkeley: University of California Press.

Shields, R. (2013). Lefebvre and the right to the open city? Space and Culture, 16, 345-348.

Strauss, A. L. (1978). A social world perspective. Studies in Symbolic Interaction, 1, 119-128. Retrieved from https://www.uzh.ch/cmsssl/suz/dam/jcr:ffffffff-9ac6-46e7-ffff-fffffdf1b114/04.22_strauss_78.pdf

Wunderlich, F. (2008). Walking and rhythmicity: Sensing urban Space. Journal of Urban Design, 13, 125-139.

Yi'En, C. (2013). Telling stories of the city: Walking ethnography, affective materialities, and mobile encounters. Space and Culture, 17, 211-223.

\section{Author Biographies}


Ossi Salin, Doc.Soc.Sc, works as a principal lecturer at the Laurea University of Applied Sciences in the Department of Research and Development. His research interests include work-life development and social network research within communities, identity research, and innovative methodologies. Recent projects have promoted social network construction and empowerment among citizens through community development.

Kaija Pesso, PhD, has worked as a principal lecturer in research and development projects at the Laurea University of Applied Sciences. Her research interests include ethics, health care and social work, community development, and social network research and methodology. 